\title{
Nostalgic memories. Qualitative reception analysis of Flemish TV fiction, 1953-1989
}

\author{
ALEXANDER DHOEST
}

Abstract

This article describes a qualitative inquiry into the historical reception of Flemish television fiction broadcast by the monopolistic Flemish broadcaster BRT between 1953 and 1989. This is a relatively homogeneous period, both in terms of broadcasting policies and fiction output. What do viewers remember of this period? Can patterns be discerned in these memories, and if so, why? To answer these questions, this research uses semistructured interviews with older viewers. First, the article discusses the particular problems of this method, mostly 'faulty' memory and nostalgic reinterpretation. Then, the findings are presented, reflecting on processes of (collective) memory formation. One clear finding concerns the selective and homogeneous nature of memories; the same few serials are remembered in similar ways by most, leading to clichéd memories of (representations of) the past.

Keywords: television, fiction, oral history, reception analysis, collective memory

This article explores how viewers experienced and interpreted the domestic serial fiction broadcast by the monopolistic Flemish broadcaster BRT between its start in 1953 and the advent of commercial broadcasting in 1989. The term 'serial fiction' is used to group all serial drama (series, serials, and miniseries) and sitcoms produced for TV, excluding single drama and television movies. First, I will present the research design and methodology, including the methodological complications of research into past reception, in particular 'faulty' memory and nostalgic reinterpretation. Then, I will present the general findings, mostly centering on the questions: what do viewers remember, and why? Do they share cul- 
tural memories, and if so, which ones? Ultimately, the aim is to ascertain to what degree television fiction, and the images it created, became part of collective memory.

\section{Qualitative audience research}

From the 1980s onwards, qualitative audience research was an important trend in media and cultural studies, often designated at the time as 'audience ethnography'. My aim here is not to summarize this vast research trend (see e. g., Abercrombie and Longhurst, 1998; Moores, 1993; Seiter, 1999), but I will go into characteristics shared by my research, as well as differences.

To start, the research presented here fits within the strand of qualitative audience research concerned with questions of interpretation; the other strand focuses more on questions about media use in the domestic context (Morley, 1998: 233). Secondly, my research shares the basic conviction that audience research should analyze the actual response of actual viewers. This cautions against assumptions about reader responses drawn from textual analysis, and instead claims a certain degree of reader activity, freedom, and therefore unpredictability. However, this freedom should not be exaggerated, as it is situated in a context of determinations and power structures. Thirdly, my research does not start from the assumption of reader resistance. As critics have noted, oppositional readings are a possibility, but Cultural Studies as a whole seems to have been overly preoccupied with aberrant audiences and readings (Jancovich and Faire, 2003: 27).

As suggested above, viewers act within a context of textual, institutional, and social restrictions. First, textual structures determine processes of meaning production. The polysemy of texts and the corresponding possibility for viewers to interpret them differently does not invalidate critical textual analysis, it only warns against making deductions from the text to the audience too easily (Ang, 1989; Fetveit, 2001). Secondly, on the institutional level, audiences do not have any direct power over the programs made available to them, so their activity must be situated within the institutional broadcasting context as well as the broader social, economical, and political context. Thirdly, readings are partly defined by the viewers' cultural competence, which is related to their social position. However, social categorizations such as class and gender are neither a given, nor a unity, and they should not be essentialized (Miller, 2002: 87-88). It is necessary to take socio-economic factors into account in a way that respects the complex intersection of multiple positions such as class, gender, ethnicity, and age (Abercrombie and Longhurst, 1998: 17). 
Following these guidelines, this project does not start from the assumption of unlimited viewer freedom, instead it takes institutional and textual constraints into account. It is anchored in previous research on the production context and textual characteristics of Flemish serial TV fiction, and it attempts to reconstruct the complexity of meaning formation in a 'holistic' way. This is an answer to calls from within media and television studies, to not study reception in isolation but to combine analyses of the different aspects of the communication process. For instance, Livingstone claims: "a research agenda is needed that connects audience research with production/texts/context research as firmly as actual audiences are, inevitably, connected with actual production/texts/ contexts" (Livingstone, 1998: 196).

\section{Historical research and media memories}

A specificity of this research is its historic nature. Instead of the traditional focus on structures and institutions, recent media history has tended to focus more on the writing of history "from below" (Anderson and Curtin, 2002: 18-20). Programs are studied as significant cultural artifacts, and everyday media use is considered constitutive of media history. This change fits within the broader 'cultural turn' in historiography, highlighting the importance of cultural narrative (Misztal, 2003: 107). In the process, popular or collective memory becomes an alternative source of historical inquiry (Popular Memory Group, 1982: 207). Indeed, memories may seem individual but they are always also social and historical, as they refer to cultural forms and social context (Bommes and Wright, 1982: 256; Misztal, 2003: 11). Collective memories are shared by groups or 'mnemonic communities', and as memories of 'who we are', they are constitutive of social identities (Conway, 2003: 311; Misztal, 2003: 133-135; Sturken, 1997: 1; Zerubavel, 2003: 3-4).

Collective memories are not fixed and stable, as they rely on reconstruction at a particular moment (Hoskins, 2001: 335). Anderson (2001: 22-23) describes memory as a site of discursive struggle. To him, memories acquire meaning in resonance with other historical constructs, and understanding the formation of memories is not to 'uncover' the past, but to analyze the formation of discourses on the past. In this context, Kuhn (2002: 9) uses the term "memory texts", to describe the recorded act of remembering, where the past is produced in the activity of remembering. In recounting the past, informants are doing "memory work", i. e., staging and performing memories (Kuhn 2004: 112). This awareness of the constructed nature of memories, however, does not imply they are pure inventions. As noted by Radstone (2000: 10), memories always have a link, however indirect, with historical experience, with 'what hap- 
pened'. Therefore, they are a valuable historical source, though one to be used with caution.

In interpreting these memory discourses regarding the past, it is important to take into account their relation to the present. Thus, Edgerton (2001: 4-5) remarks on the preoccupation with the creation of a "usable past", using the past to clarify the present. Popular memory, then, has less to do with accuracy than "using the past as a kind of communal, mythic response to current controversies, issues, and challenges" (Edgerton, 2001: 5). In a similar vain, Spigel opposes academic history to popular history, which simplifies the complexity of historical events in creating "history for the present", speaking to the needs of contemporary life: "Popular memory is a form of storytelling through which people make sense of own their lives and culture" (Spigel, 1995: 21). Samuel (1994: 6) agrees, stating that popular memory deals in "broad-brushed contrast between 'now' and 'then', 'past' and 'present'".

Popular or collective memory is partly constructed by cultural forms, which institutionalize memory into "cultural memory" (Misztal, 2003: 12; Sturken, 1997: 3). As many authors note, the representations formative of collective memory are increasingly produced by popular culture and mass media (Hoskins, 2001: 334; Lipsitz, 1990: 36; Middleton and Edwards, 1990: 4; Misztal, 2003: 22; Popular Memory Group, 1982: 209). As Kansteiner (2004: 576) adds, in order to study collective memories it is important not only to analyze such representations, but to also look at how people use and identify with them.

However, there is little information available on historic reception, a field which is academically underdeveloped. This fits within a broader problem in television historiography, where the resources are limited and access is often restricted (Corner 2003: 277). One method to reconstruct past reception is historical reception analysis. Qualitative audience analysis, in general, interprets audience interpretations, considering them not as transparent renditions of the 'truth' about media use but rather as discursive constructions of reality. Similarly, historical reception analysis deals with interpretations of the past, not aiming to reconstruct 'the' past but rather to study its discursive construction in viewer memories ${ }^{1}$.

Methodologically, historical reception analysis relies on oral history interviews. A problem and point of criticism of such research concerns the limitations of memory. With the analysis going back as far as 1953, the interviewees may not remember much. Moreover, they may (nostalgically) reinterpret the past in view of subsequent evolutions, in particular the introduction of commercial broadcasting. However, beside memories there are few alternative sources of qualitative information on past reception. More importantly, the opposition between memories and 'objective' historical sources is outdated, as all sources are narrative con- 
structions based on 'subjective' retrospection (De Wever and François, 2003: 17; Richards, 2003: 343). Therefore, the question is not so much whether memories are accurate, but rather why they take a particular shape (Middleton and Edwards, 1990: 3). In this research, viewer responses are not considered a transparent source of information regarding the past, but as an indication of the workings of memory. The basic assumption is that those programs and images that are best remembered are probably the ones that left the strongest mark and became part of collective memory. Therefore, salience rather than accuracy is the characteristic looked for in memories.

\section{Research design}

The researched period is limited to the era of the public broadcasting monopoly, from 1953 until 1989. Despite the broad time span, this was a relatively homogeneous period in terms of production practices and program output. As described elsewhere, the broadcasting philosophy remained relatively constant throughout this period (Dhoest 2004), which lead to a very homogeneous domestic fiction supply (Dhoest 2003). To study its reception, viewers were interviewed who had witnessed the introduction of the medium. At the start of this project, television in Flanders was exactly 50 years old, so viewers over 60 were interviewed. This leads to a relatively homogeneous age group, hence the analysis had to take the characteristics of this viewer group into account. Most research on older viewers finds they combine criticism on the current supply of television programs (in particular the level of 'sex and violence') with nostalgia for former programs of their younger years (Gauntlett and Hill, 1999: 200-201; Hackl, 2001: 210; Healey and Ross, 2002; Tulloch, 1992: 181; van der Goot, Beentjes, and van Selm, 2006).

The interviews were semi-structured, following an interview guide with fixed starting questions, but leaving space for the respondents' own stories. The interview was divided into three parts, moving from an open investigation of general memories to detailed questions on specific programs, using a list of titles to identify the most 'significant' and influential images. A total of forty viewers were interviewed. Although representativeness is not an objective in qualitative research, when making an argument about the 'common viewer', it is important to aim for a fair representation of variation within the population. As to age, twenty respondents were under seventy, twenty were seventy or older, with members of the younger group being children or adolescents at the start of television, while members of the older group were grown-ups at that time. In total, twenty men and twenty women were interviewed (ten of each in both age groups), in contrast to most earlier 'ethnographic' and 
historical reception research, which has tended to prioritize female viewers (e. g., Hobson, 1982, Ang, 1985, Stacey, 1998, Kuhn, 2002). One of the side effects of the focus on female viewers is the lack of information on differences between male and female readings. Finally, to assess class positions, a variation of educational and occupational backgrounds was aimed for, about 50/50 higher education/intellectual jobs and lower education/manual jobs.

One factor complicating this analysis is the celebration of fifty years of television in 2003. On this occasion, many 'archive' programs were broadcast, using fragments from older programs to look back upon broadcasting history. More significantly, in the afternoon many old series and serials were repeated, which may have affected memories. For one, the chances of remembering those programs which were repeated were increased, a notion which is in line with the general positive influence of repetition on memory (De Wever and François, 2003: 11). Moreover, the process of repeated viewing could lead to the revision of former memories and evaluations. Therefore, the respondents were asked if they watched the reruns, which ones and how often. This information was taken into account in the analysis. Throughout this text, information will be given on reruns of the remembered programs.

This being said, it is important to put the reruns in perspective, as the ratings for the afternoon reruns were not high, some 130000 on average, although, admittedly, these were mostly older viewers ${ }^{2}$. In the research discussed here, not many interviewees had watched the reruns, and those few who had only watched a few single episodes. The analysis also showed that some well-remembered series were not repeated and vice versa. More fundamentally, the reruns do not need to be seen as a problem as the very idea of 'unmediated' memories, 'distorted' by television's interference, is highly fallacious. Memories are not stored in a fixed form and subsequently retrieved. Rather, memories are narrative constructions, in this case for the sake of research, always dependent on many factors and susceptible to influences. One mediating factor for media memories is the process of memory making by the media themselves. By repeating programs, but also by referring to them or showing clips, television makes its own history, thereby reinforcing - and actually forming - certain viewer memories. In this light, the celebrations, while certainly influencing memories, are not an anomaly but rather one of many mediating factors to be taken into account.

\section{Favorite memories}

This section of the analysis deals with the questions: which programs and images are remembered? What characterizes these particular images? 
Do they constitute shared cultural memories? To situate these findings, an overview of the domestic fiction production is useful, although there is no space to do justice to its complexity here. A few general patterns will be sketched, and throughout the text more specific examples will be given. First, although domestic fiction was a symbolically important program category, the actual output was limited because of financial constraints. In the 1953-1989 period, only 32 series and serials were produced, although admittedly one-off productions were also well-represented, particularly in the first decades. Second, 'serious' drama was most important in this period (with seventeen out of 32 productions, as opposed to only eleven comedies). Thirdly, genre boundaries were not clearly established from the start, many early productions including dramatic and comic elements. From the 1970s, the most prominent genre was 'quality drama', mostly literary adaptations (15 out of 32) situated in the past (twenty out of 32). Most common were period serials situated in early $20^{\text {th }}$ century rural Flanders, showing the life of the common agricultural workers. The language used was strongly dialectical, and the Flemings were represented as stubborn, hard workers (Dhoest 2001a, 2001b, 2003).

As to the viewer memories, a first clear finding concerns their selective nature. There is a strong consistency in the fiction remembered, not only spontaneously in the first part of the interview, but also when a list of titles is shown. Some series and serials are consistently remembered, while others are only remembered by their title, if at all. Generally, the programs that are remembered are popular, long running and humorous. Viewers mostly remember their general atmosphere, themes, basic situation, and characters or actors, rather than specific plot events or storylines.

The fiction program most spontaneously and vividly remembered is Schipper naast Mathilde ('Skipper near Mathilde', 1955-1963). This was the first real series, which had the monopoly of serial drama for a massive eight years and 185 episodes. It was a very popular show, with strong comic types and a mild but eccentric humor. Revolving around retired skipper Matthias and his gentle sister Mathilde, it was both a proto-soap opera showing the daily life of common people in a small Flemish village, and a proto-sitcom exploiting a comic situation in every installment. The vividness of memories of this series is all the more remarkable, because it has not been rerun since, as it was broadcast live from the studio. Nevertheless, 33 out of the forty interviewees spontaneously name this series, and the remaining seven remember it when seeing the list of titles.

The reasons for the centrality of Schipper in television memories are closely related to the context of early television viewing (see also Dhoest 
2006). For starters, Schipper was very widely watched, many respondents remembering that "everybody watched it". "Everybody" is relative, particularly for the early years, as television sets were few at that time, but many went to watch elsewhere. The viewers also dearly loved it, and indeed, many respondents claim their best memories are of Schipper. They praise its good acting and they remember its gentle tone and pleasant atmosphere, its simplicity, coziness, and innocence. One respondent, a 75-year-old seamstress, links this to a high degree of recognition: "They represented everything as we have known it in our own lives. In my view, it was much more spontaneous, more ordinary, not as much sex and not as contrived" 3 . This response witnesses to the nostalgia inherent in memories of Schipper, but also to the importance of ordinariness. "Realism" and "recognition" are other recurring criteria. For instance, a 74-year-old female employee remarks:

Everybody liked it, because it was so real, and so recognizable. (...) To me, it was daily life, the comings and goings of everyday life. (...) Schipper naast Mathilde was so recognizable. It was a very common household with a warm atmosphere. That was easy to recognize.

This is a recurring theme in memories about this period, most interviewees claiming to have the best memories of programs that dealt with normal everyday life.

During most of its long run, Schipper was broadcast bi-weekly in a fixed slot, which made it one of the first habitual shared viewing experiences. The very fact that it was the first domestic series ever also contributes to its special status. For many, memories of Schipper coincide with the first memories of television, which greatly adds to their salience. Schipper was also the only serial drama offered for a long time, and viewers were not used to very much yet, as many respondents stress. Moreover, Schipper was broadcast in the youth or young adult life of many respondents, so it feeds into the general nostalgia for memories of one's youth. Many respondents had more extensive and detailed memories of this period than of subsequent drama, which may be, among other things, due to the particular and formative nature of this period in their lives. Indeed, memory research suggests that memories of late adolescence and early adulthood tend to be stronger than those of subsequent periods, a phenomenon that is called the "reminiscence bump" or "peak" (Misztal, 2003: 85; Schacter, 1996: 297-298).

Finally, it is important to add that Schipper has acquired somewhat of a mythic status over the years. Although (or perhaps conversely: because) it was never rebroadcast, it is always used as a shorthand reference to early Flemish TV drama, epitomizing a whole period. This 
mythic status of Schipper is highly nostalgic, as it is linked to the general sense that "before things were better", and in particular, "television was better back then", which fits within the tendency of popular memory to oppose past and present mentioned above. Indeed, these older viewers consistently and spontaneously compare the past to the present, a tendency also reported by van der Goot et al. (2006). The mythology concerning Schipper also illustrates the collective nature of memories, creating a shared identity in the process, as noted by Kuhn:

Viewer memory texts may create, rework, repeat and recontextualise the stories people tell each other about the kind of lives they have led; and these memory-stories can assume a timeless, even a mythic, quality which may be enhanced with every retelling. (Kuhn, 2002: 11)

A second central program in viewer memories of Flemish TV fiction is the serial Wij, heren van Zichem ('We, the lords of Zichem', 1969). It was spontaneously named by half of the respondents, and when presented with a list of titles, all the others also vividly remembered it. Many of them (15) have seen part of the reruns, which both cautions against taking the vividness of these memories at face value, and testifies to the continued popularity of the program. Like Schipper, Heren is a nostalgic village drama, in this case based on the novels of author Ernest Claes. It is less humorous than Schipper, as it has a mixed comic and dramatic tone. It also contains some memorable comic types and situations, but equally important are social themes, in particular relating to processes of modernization. Like Schipper, Heren was extremely popular and it was almost universally watched. The first audience research in 1969 suggests a massive audience of 3120000 viewers (on a population of 5,5 million), a viewing rate of $78 \%$ on average (BRT, 1969: 36).

Viewer memories of Heren are predominantly positive and besides Schipper, it is the program the respondents have the best memories of. Many viewers comment on the good acting and they remember many characters and actors. As with Schipper, recognition, ordinariness, and realism are central terms in viewer memories. An important strength of Heren is the fact that it represented a world many viewers had know themselves or through their parents' and grandparents' memories. For instance, a 68 year old male factory worker says: "That real old farmer life, those small villages and that kind of life, it was well represented. Really right, like in our young years, as we had lived it”. Recognition, in this case, is closely linked with nostalgia of the 'simple', and 'more natural' country life. For instance, a 79-year old teacher says she has fond memories of the 'natural', 'ordinary', and 'real' life in Zichem, adding: 
It was more rural. Perhaps not for people from the city, but for people from the countryside that's a memory of which you say: ah yes, the communal life of the past. It doesn't happen anymore, now everyone is in their own little house, but back then you lived with the neighbors. They were all people living together and I think that's missing nowadays.

This account is representative of the overall nostalgic memories of a serial that took a nostalgic look back at the past itself. These memories fit within a general tendency of older viewers to prefer gentle fiction related to the/their past (van der Goot et al., 2006: 454-455). The double nostalgia identified above is also exemplary of the tendency of contemporary nostalgia, which is not only propagated by mass media but whose objects are often media creations (Davis, 1981: 221). This cultural nostalgia links to the above mentioned past-present opposition in that it is considered as a symptom of contemporary malaise, or the sense that the present is deficient (Chase and Shaw, 1989, 2-3).

\section{Patterns of remembrance}

Discussing all the memories of other series and serials separately is outside the scope of this article, but it seems useful to sketch some general patterns. First, as to the other series and serials spontaneously remembered, the list is quite short. Out of the 32 Flemish series and serials broadcast between 1953 and 1989, apart from Schipper (33 mentions) and Heren (21 mentions), only six more programs are mentioned spontaneously, each only by three to five respondents. This reconfirms the centrality of Schipper and Heren, and the selectivity of memories. Moreover, five of these programs were repeated for the celebration of fifty years of television, which cautions against rash conclusions concerning their memorability. Again, however, one could argue that they were repeated because they were still alive in collective memory. Of the remembered programs, two are comedies continuing the tradition of Schipper, and three are rural dramas in the vein of Heren. I would like to argue that these programs are remembered partly because they fit into a general, synthetic image of fiction of this period. They became part of the mythology, while others have been forgotten both by viewers and by the television institution itself.

When shown a list of titles, a majority of respondents (34 to forty) remember the same eight programs, while more than thirty respondents remember another four programs. Apart from the failed successor of Schipper, the contemporary comedy De kat op de koord ('Cat on a rope', 1963), which none of the respondents remember, all the programs of the 1960s are among the best remembered, including those that were not 
repeated. Conversely, consistently fewer viewers remember programs from the 1980s, with the exception of reruns. So contrary to what one might expect, the period furthest removed in time is actually best remembered, which testifies to its special status both in the lives of the respondents and in television history. Another factor that has a positive influence on memories is the number of episodes. Both Schipper (185) and Heren (26) were long-running programs according to the standards of their time, and indeed all long-running programs are well remembered. However, a long run is not necessary, as some well-remembered programs only had six episodes.

As to content, viewer memories parallel the general textual patterns identified above; i. e., eight of the 12 best-remembered programs are historic, and while the press often criticized the amount of historic productions in this period, the viewers do not seem to share this view. Similarly, the strong reliance on literary sources was also excused - or even appreciated - by the viewers: nine out of the 12 best-remembered programs were literary or theatrical adaptations. Far from being estranged from the viewers' interests, as press criticism would have it, the broadcasters seem to have been in touch with the audience's taste.

As to style, the more 'arty' productions are poorly remembered and their mention sometimes even leads to disinterested or outright hostile responses. For instance, Rubens, schilder en diplomaat ('Rubens, painter and diplomat', 1977) was a very pictorial and artful production. While the serial was sold to fifteen countries and was widely acclaimed, it was not very successful in Flanders (BRT, 1978: 62). Most respondents do not remember much of the serial, apart from its title (seventeen mentions), and even these memories are unreliable as they often seem to be based on the - socially desirable - recognition of the name of Rubens. Some respondents have good memories of the serial, but the general gist of the memories is dismissive, remembering it as "too learned", "too heavy", and "fake". These responses are widely shared across gender and class borders. For instance, a sixty-year old female university professor remembers it was not a huge success: "I do remember that people thought it was too static and majestic, and as such, less corresponding to the Flemish character". It seems that most viewers, regardless of education, preferred programs with a more popular tone.

As to production, the fiction of this period was the product of 'modern', culturally nationalist broadcasting policies, aiming to stimulate Flemish culture and identity. This is the time of the modern, educational PBS, governed by middle-class intellectuals with a background in the arts and in education (Dhoest, 2004; Van den Bulck, 2001). Interviews with broadcasters of the time demonstrate that it was their intention to make viewers familiar with the Flemish historic and literary heritage. On 
first sight, they seem to have been successful, as the viewers liked watching the ensuing historic and literary drama. However, it is important to qualify this parallel between producer intentions and viewer interest, as historical and literary drama was only successful to the degree that it was popular. This confirms the view that the drama producers were successful in spite of, rather than due to, their personal preference for serious, literary historical drama. This is even more clearly proven by the success of the genre most broadcasting officials looked down on, namely comedy. Beside Schipper, this category includes the classics Slisse en Cesar ('Slisse and Cesar', 1977) and De collega's ('The colleagues', 1978). Both drew extensive audiences and are well remembered by 39 respondents. Even for comedy, realism and recognition are often named as important reasons to like and remember the program. For instance, talking about Slisse en Cesar, a 90-year old male farmer comments: "It was really beautifully played and it was so well-acted that you would think it was real. You could recognize all the things you saw in everyday situations".

\section{Why we remember}

Regarding the reasons for the remembrance of these particular series, many have been pointed out throughout this text. For starters, programs tend to be better remembered to the degree that more viewers watched them. Some, like Schipper, were even remembered by respondents who had not watched them consistently, if at all, which underlines their central position in cultural imagination and memory. Needless to say, respondents mostly remember programs they actually watched. This, in turn, implies that they could watch and that they wanted to. Most respondents state a clear preference for Flemish drama over imported fiction, mostly because of the language. A 83-year old male teacher links language to recognition: "I think it appealed more to us, because it was more about our own life, we could recognize ourselves much more in it. Not to forget the intelligibility, the language". Particularly during the first years, the viewing of Flemish material was also a novelty. Thus, a sixty year old journalist ascribes his preference for Flemish drama to recognition and novelty:

I found it fascinating, because you saw Flemish actors on your little screen, while you didn't know that very well, because ... There weren't many Flemish films at that time, they hadn't taken off yet (...). It was quite unique, suddenly seeing Flemish actors on screen, talking a language you understood, while in the cinema you only saw French movies, Italian movies, American movies ... 
Choice is also a determining factor in another way, as many respondents claim they often watched a program because there was not much else on. This reason is often invoked for the early years, but limited choice played a role throughout the period of monopolistic broadcasting, up until the late 1980s. During this time period, there was only one Flemish broadcaster, with a second channel coming into existence in 1977. However, the rapid spread of cable distribution in the 1970s lead to a decreasing market share for the BRT, from $75 \%$ in 1970 , to $62 \%$ in 1980 , further lowering to $57 \%$ in the late 1980s (BRT 1970-1988). Most attractive were the more popular Dutch channels, drawing a market share of about $25 \%$ from 1975 on. Indeed, some respondents admit they started watching less Flemish drama when the choice of channels increased.

Besides having watched a program, having liked it is another factor facilitating remembrance. The second is partly related to the first, for as many respondent claim: 'if we didn't like it, we didn't watch it'. However, because of the limited choice viewers often watched programs they were not very enthusiastic about. This echoes Brunsdon's (1989: 126) remark, that 'active' audiences may actually only be making the best of a bad job, but that they ultimately prefer watching other programs than the ones available. However, viewers mostly watched what they liked and the most crucial factor in the evaluation of fiction is its link with reality. As mentioned earlier, viewers often praise the realism of programs they remember, claiming they could recognize reality and themselves in it. Throughout the interviews, the importance of links to the own, everyday world of the viewers is confirmed. This is most clearly the case when there are actual links between television and the life of the viewers.

In this context, Bourdon (1995: 27-29) uses the term "souvenirs-passerelle" ('footbridge-memories'), to describe memories related to the moment when television and private life meet. This is most strongly the case when an individual participates in a program, but also when a television figure passes in the viewer's life, or when a program deals with a subject the viewer knows and can judge. In my interviews, a similar distinction can be made. Firstly, three respondents were involved as extras and musicians in Paradijsvogels ('Birds of Paradise', 1979), and they are all huge fans with fond and detailed memories. Moving on to Bourdon's second variation, a television figure passing in daily life, another respondent personally knew the writer of Paradijsvogels, which equally created a strong bond with the program. A 60-year old journalist knew one of the actresses in De collega's, which is the only program he claims to have stayed home for and the one he has the best memories of.

Most frequent were less direct forms of recognition, often to do with regional familiarities, such as authors or actors living nearby. For in- 
stance, the cast of De collega's mostly belonged to a theater company based in Mechelen, the Mechels Miniatuurtheater (MMT). Two residents of Mechelen name this as an important reason to watch and remember the series. At a still more general level, viewers feel more involved and therefore have stronger memories of programs set in their region. For instance, a sixty year old male stockbroker living near Zichem admits this creates a bond with Heren: "You feel a bit like a party involved. First, because you live near, you feel a little proud, like the people of the region who had played a part. Also because you find everything in it used to happen here". As stated by a 73-year old housewife, this involvement positively influences remembrance: "It sticks more clearly in your memory when it's shot nearby". This response suggests that beside cultural proximity, a factor often used to explain the appeal of domestic fiction, literal geographic proximity is also important. Most generally, many memories are linked to recognition of elements in the respondent's personal life. For instance, an important element in the fond memories of Schipper is its image of a simple and cozy Flanders, the respondents stressing the innocence and ordinariness of the protagonists and the gentility of small-village life.

\section{Confusion and synthesis}

Across the board, the best-remembered and most appreciated programs are nostalgic period serials about Flemish village life in the first half of the $20^{\text {th }}$ century. Schipper naast Mathilde and Wij, heren van Zichem are most vividly remembered, while memories of other programs tend to be vaguer and to gravitate towards central programs, in particularly Heren. Thus, programs are often described as "something like" Heren. For instance, talking about Een mens van goede wil ('A man of good will', 1973), a 60-year old female professor asks: "Wasn't that like The lords of Zichem, in terms of atmosphere and time setting?". Often, the responses also betray confusion as to where particular characters and plotlines belong. Most often, plotlines of Heren pop up in memories of other serials, a confusion sometimes addressed by the respondents, such as this sixty year old male broker:

I remember it was about a rich farmer and a poor farmer, and their children were in love or married and it all got out of hand. I also think someone was killed, but I'm not sure. I could mix it up with another series.

Heren is also confused with films based on the same material. For instance, one of the books it is based on is De Witte, an all-time favourite 
of Flemish literature, which has been successfully adapted into two films. De Witte ('Whitey') is a prototypical character from the literature of Ernest Claes, a blonde-haired rascal with a good heart. Quite a few respondents mention they have read the book, and some even remember the series by the title De Witte and recount anecdotes about De Witte, present in the serial but equally in the book and films. Arguably, there is some confusion between book, films and serial.

Heren is further confused with Het gezin van Paemel ('The Van Paemel family'), another 'classic' peasant film (based on a well-known theater play). For instance, a 79-year old female schoolteacher follows up her memories of Heren with a description of Het gezin van Paemel and the similarities both share:

The common people depending in every way on the lord of the castle, as slaves or farmers, who had to work for nothing at all and give all their revenues to the lord. The common people who had to earn their bread living in a poor little house owned by the lord, and in the end they had to crouch for the lord and say "thank you for all the work we have done".

Another serial, De Leeuw van Vlaanderen ('The Lion of Flanders', 1985), is badly remembered in itself, but is often associated or even confused with Heren. Indeed, in Heren De Witte reads the book De Leeuw van Vlaanderen, recounting a mythologized Flemish battle, and afterwards acts it out with his friends. For instance, a 69-year old tradeswoman calls De Leeuw van Vlaanderen "something in the style of Wij, heren van Zichem" - which it was not, as it was a medieval war drama.

Clearly, memories are synthesized and gravitate towards a central serial and its image of Flanders. To the creation of a cliché image by television corresponds a cliché memory by the viewers. This process of synthesis is certainly influenced by the broader intertextual discursive context, with the successful regional 'heimat' literature at the centre. Beside adaptations in film and television, there are also links to theatrical writing and visual conventions in painting, as well as broadly circulating conceptions of Flemish history, national character and culture (in everyday parlance but also in historiography, political discourse etc.). Thus, the memorability of this particular portrayal of Flanders partly depends on its correspondence to and confirmation of pre-existing discourses and representations.

A similar process of synthesis is present in memories of actors and characters. On the one hand, actors are confused because of a similar physique or role they played. Thus, viewer memories echo the process of typing predominant in drama at the time (Dhoest, 2001b). On the 
other hand, actors are often strongly identified with particular roles, and are remembered by that name. For instance, Nand Buyl, who played the skipper in Schipper, is erroneously remembered to have played in many other series. There is most confusion regarding Heren, as many of its actors are wrongly remembered to have appeared in other series. Actors and characters seem to be remembered according to type, in which case the strongest example of the type tends to replace memories of other examples: one becomes the archetypical village priest, another the archetypical motherly woman. This formation of character types in memories further supports the conclusion that viewers remember a cliché image of Flemish TV drama.

\section{Conclusion}

Reviewing the respondents' memories, some broad patterns appear. Most relevant to the present research is the selectivity of memories, which consistently include particular programs, images, and aspects to the exclusion of others. Respondents tend to remember and like the same serials, mostly Schipper and Heren, and more generally the rural period dramas of the 1960s. These programs clearly became part of collective memory. Moreover, the respondents mostly use terms like realism and recognition to explain their preference for these programs, which suggests they used them to reflect on reality. This is evidence of a strongly 'referential' reading, the term used by Liebes and Katz (1990) for readings stressing the relationship between programs and real life. More generally, the eagerness to talk about these serials, the fondness of memories, and the stress on the importance of a recognizable language also illustrate the crucial role of cultural proximity in the reception of domestic fiction and its strong link to cultural identity.

The interviews also confirm the importance of the factors of determination summed up in the discussion on reception analysis. First, on the textual level, there is a close parallel between viewer memories and textual structures of meaning. The dominant genre of period literary adaptations about rural Flanders is best remembered, to the exclusion of programs in other genres. As mentioned before, viewers often synthesize elements from different series and confuse actors and characters, mirroring textual processes of genre formation and typing. The memories of this drama are not particularly detailed (or accurate, for that matter), but they are very salient and vivid. Rather than reading - or remembering - against the grain, the respondents go along with the image of Flanders proposed by the series, to the point that they melt different series together in one synthetic image of a poor, rural Flanders peopled with simple, ordinary people. As mentioned above, this image fits within 
wider discourses about and representations of Flanders and Flemishness.

Second, on the institutional level, the respondents comment on the limited choice of programs, particularly in the early years of television. This confirms that ultimately, any viewer activity - including remembering - is determined by the programs actually broadcast. This, in turn, is determined both by broadcasting policies and by a host of practical conditions (see Dhoest, 2004). The success and fond memories of rural period drama seem to indicate that the broadcasters were in touch with viewer preferences, but analyzing the interviews it becomes clear that the programs were not necessarily appreciated for the reasons the broadcasters had in mind. For them, the reliance on classic novels was meant to make the viewers familiar with Flemish literature, and period drama was meant to make them familiar with their past. However, what the viewers remember is not as much literature and history, but rather the gentle, humorous tone, and the nostalgic image of village life.

Thirdly, regarding cultural competence and social position, the research strategy was not to deliberately look for evidence of the role of gender and class, but to take into account the combination of multiple social positions. This may partly explain why, when analyzing the interviews, gender and class seem not to be as determining as other studies suggest. As to gender, there are no systematic differences between the memories of men and women, which suggests that the analyzed program category did manage to unite viewers. Indeed, when they talk about their preferences, Flemish period drama sounds like a little gendered category (as opposed to the 'feminine' soap or the 'male' crime drama). Similarly, class does not have the expected predictive value, as both respondents of 'high' and 'low' education and employment remember the same programs with the same fondness. As with gender, period drama seems to cross social borders and to create genuinely shared memories.

On the whole, the findings suggest a strong compliance of viewers with the images created by the broadcasters. Resistant readings were not deliberately looked for, but they also did not arise in the interviews and the viewer memories turned out to be predominantly positive. This may be partly the product of nostalgia, as memories of rural period drama may be instrumental in constructing a 'usable' opposition between the 'good' past and the 'bad' present. Most respondents spontaneously criticize current television, often reduced to the ubiquity of 'sex and violence', which may lead them to prioritize their good memories of the past. However, the viewers' compliance also suggests that resistant readings are not as common as some early ethnographic research suggested. Another conclusion would be that the broadcasters were successful in creating ideological consent for their image of the Flemish past, a selec- 
tive image based on a particular literature. The image they created was indeed a construction, forming a strong discourse about the Flemish past, which through constant repetition became part of common sense. However, the great success and recognition of this image suggests it did connect to viewer images and memories. Rather than an image unilaterally imposed by any 'dominant class' of intellectuals, it seems to have been an image drawing on popular culture and memories, reconfirming them in the process. Only through such a (Gramscian) process of creating hegemonical consent could television fiction become such a clear object of collective memories.

\section{Acknowledgments}

This research was realized with the support of the Fund for Scientific Research (FWO) Flanders. The author wishes to thank the anonymous reviewers for their useful comments.

\section{Notes}

1. For an overview of the literature on television memories, see Dhoest, 2005. Two interesting accounts on cinema memories can be found in Stacey (1998) and Kuhn (2002).

2. This represents a market share of $36 \%$ on average, because of the low viewing at 2PM (source: VRT Research Department).

3. The interview transcripts are literal translations by the author. To situate the interviewee, his or her age, gender and (former) job are mentioned. The quotations are representative of the overall patterns and average arguments in the interviews, but of course not all interviewees agree on all accounts. However, partly because of length restrictions, this article focuses on general patterns, so individual extreme or divergent responses are not dealt with.

\section{References}

Abercrombie, N. and Longhurst, B. (1998). Audiences: A sociological theory of performance and imagination. London: Sage.

Anderson, C. and Curtin, M. (2002). Writing cultural history: The challenge of radio and television. In N. Brügger and S. Kolstrup (Eds.), Media history: Theories, methods, analysis (pp. 15-32). Aarhus: Aarhus University Press.

Anderson, S. (2001). History TV and popular memory. In G. Edgerton and P. Rollins, P. (Eds.), Television histories: Shaping the collective memory in the media age (pp. 19-36). Lexington, KY: University Press of Kentucky.

Ang, I. (1985). Watching Dallas. London: Methuen.

Ang, I. (1989). Wanted: Audiences. On the politics of empirical audience studies. In E. Seiter, H. Borchers, G. Kreutzner, and E. M. Warth (Eds.), Remote control: Television, audiences, and cultural power (pp. 96-115). London: Routledge.

Bommes, M. and Wright, P. (1982). "Charms of residence": The public and the past. In R. Johnson, G. McLennan, B. Schwarz, and D. Sutton (Eds.), Making histories: Studies in history-writing and politics (pp. 253-301). London: Hutchinson. 
Bourdon, J. (1995). Le flash et le papier peint: Mémoires de télévision. In J.-P. Esquenazi (Ed.), La télévision et ses téléspectateurs (pp. 13-31). Paris: Ed. L'Harmattan.

BRT (1969). Enkele algemene vaststellingen en ontwikkelingen van het kijk- en luisteronderzoek. Brussel: BRT.

BRT (1970-1988). Jaarverslag [Annual Report]. Brussel: BRT.

Brunsdon, C. (1989). Text and audience. In E. Seiter, H. Borchers, G. Kreutzner, and E. M. Warth (Eds.), Remote control: Television, audiences, and cultural power (pp. 116-129). London: Routledge.

Chase, M. and Shaw, C. (1989). The dimensions of nostalgia. In M. Chase and C. Shaw (Eds.), The imagined past: History and nostalgia (pp. 1-17). Manchester: Manchester University Press.

Conway, B. (2003). Active remembering, selective forgetting, and collective identity: The case of Bloody Sunday. Identity: An International Journal of Theory and Research, 3(4), 305-323.

Corner, J. (2003). Finding data, reading patterns, telling stories: Issues in the historiography of television. Media, Culture and Society, 25, 273-280.

Davis, F. (1981). Contemporary nostalgia and the mass media. In E. Katz and T. Szecskö (Eds.), Mass media and social change (pp. 219-229). London: Sage.

De Wever, B. and François, P. (2003). Gestemd verleden: Mondelinge geschiedenis als praktijk. Schaarbeek: Vlaams Centrum voor Volkscultuur.

Dhoest, A. (2001a). Peasants in clogs: Imagining Flanders in television fiction. Studies in Popular Culture, 23(3), 11-24.

Dhoest, A. (2001b). National identity as normality: Representation and typing in Flemish television fiction. InterSections: The Journal of Global Communications and Culture, $1(2), 15-26$.

Dhoest, A. (2003). Reconstructing Flanders: The representation of the nation in Flemish period drama. Communications: The European Journal of Communication Research, 28, 253-274.

Dhoest, A. (2004). Negotiating images of the nation: The production of Flemish TV drama, 1953-1989. Media, Culture and Society, 26(3), 393-408.

Dhoest, A. (2005). Nostalgie en collectief geheugen: Kijkerherinneringen aan Vlaamse tv-fictie. Tijdschrift voor Mediageschiedenis, 8(1): 41-62.

Dhoest, A. (2006). "Everybody liked it": Collective memories of early Flemish television fiction.Particip@tions, Journal of audience and reception studies, 3(1). Available (consulted 31 October 2006) at: http://www.participations.org/volume\%203/ issue $\% 201 / 3$ _01_dhoest.htm

Edgerton, G. (2001). Television as historian: A different kind of history altogether. In G. Edgerton and P. Rollins, P. (Eds.), Television histories: Shaping the collective memory in the media age (pp. 1-16). Lexington, KY: University Press of Kentucky.

Fetveit, A. (2001). Anti-essentialism and reception studies: In defense of the text. International Journal of Cultural Studies, 4(2), 173-199.

Gauntlett, D. and Hill, A. (1999). TV living: Television, culture and everyday life. London: Routledge.

van der Goot, M., Beentjes, J. W. J., and van Selm, M. (2006). Older adults' television viewing from a life-span perspective: past research and future challenges. Communication Yearbook 30, 431-469.

Hackl, C. (2001). Fernsehen im Lebenslauf: Eine medienbiographische Studie. Konstanz: UVK Medien.

Healey, T. and K. Ross (2002). Growing old invisibly: Older viewers talk television. Media, Culture and Society, 24, 105-120. 
Hobson, D. (1982). Crossroads: Drama of a soap opera. London: Methuen.

Hoskins, A. (2001). New memory: Mediating history. Historical Journal of Film, Radio and Television, 21(4), 333-346.

Jancovich, M. and Faire, L. (2003). The place of the audience: Cultural geographies of film consumption. London: BFI.

Kansteiner, W. (2004). Nazis, viewers and statistics: Television history, television audience research and collective memory in West Germany. Journal of Contemporary History, 39(4), 575-598.

Kuhn, A. (2002). An everyday magic: cinema and cultural memory. London: IB Tauris.

Kuhn, A. (2004). Heterotopia, heterochronia: place and time in cinema memory. Screen, 45(2), 106-114.

Liebes, T. and Katz, E. (1990). The Export of Meaning. Cross-Cultural Readings of Dallas. New York: Oxford University Press.

Lipsitz, G. (1990). Time passages: Collective memory and American popular culture. Minneapolis, MN: University of Minnesota Press.

Livingstone, S. (1998). Audience research at the crossroads: The 'implied audience' in media and cultural theory. European Journal of Cultural Studies, 1(2), 193-217.

Middleton, D. and Edwards, D. (Eds.) (1990). Collective remembering. London: Sage.

Miller, T. (Ed.) (2002). Television studies. London: BFI.

Misztal, B. (2003). Theories of social remembering. Maidenhead: Open University Press.

Moores, S. (1993). Interpreting audiences: The ethnography of media consumption. London: Sage.

Morley, D. (1998). Domestic relations: The framework of family viewing in Great Britain. In R. Dickinson, R. Harindranath, and O. Linné (Eds.), Approaches to audiences. A reader (pp. 233-244). London: Arnold.

Popular Memory Group (1982). Popular memory: theory, politics, method. In R. Johnson, G. McLennan, B. Schwarz, and D. Sutton (Eds.), Making histories: Studies in history-writing and politics (pp. 205-252). London: Hutchinson.

Radstone, S. (Ed.). (2000). Memory and methodology. Oxford: Berg.

Richards, H. (2003). Memory reclamation of cinema going in Bridgend, South Wales, 1930-1960. Historical Journal of Film, Radio and Television, 23(4), 341-355.

Samuel, R. (1994). Theatres of Memory, vol.1: Past and present in contemporary culture. London: Verso.

Schacter, D. (1996). Searching for memory: The brain, the mind, and the past. New York: BasicBooks.

Seiter, E. (1999). Television and new media audiences. Oxford: Clarendon Press.

Spigel, L. (1995). From the dark ages to the golden age: Women's memories and television reruns. Screen, 36(1), 12.

Stacey, J. (1998). Star gazing: Hollywood cinema and female spectatorship. London: Routledge.

Sturken, M. (1997). Tangled memories: The Vietnam War, the AIDS epidemic, and the politics of remembering. Berkeley, CA: University of California Press.

Tulloch, J. (1992). Approaching the audience: The elderly. In E. Seiter, H. Borchers, G. Kreutzner, and E. M. Warth (Eds.), Remote control: Television, audiences, and cultural power (pp. 180-203). London: Routledge.

Van den Bulck, H. (2001). Public service television and national identity as a project of modernity: The example of Flemish television. Media, Culture and Society, 23(1), 53-69.

Zerubavel, E. (2003). Time maps: Collective memory and the social shape of the past. Chicago, IL: University of Chicago Press. 